\title{
Congenital dynamic cervical instability in a dog: the role of computed tomography and 3D printing to plan and optimize the surgical approach
}

\author{
Instabilidade dinâmica cervical em um cão: papel da tomografia \\ computadorizada e da impressão 3D no planejamento e \\ otimização do procedimento cirúrgico
}

\begin{abstract}
Maria Eduarda dos Santos Lopes Fernandes*, Ricardo Siqueira da Silva², Leonardo Rodrigues de Lima², Lucas Rego Ramos ${ }^{3}$, Anna Julia Rodrigues Peixoto', Gabriela Wacheleski Brock' ${ }^{4}$ J José Eduardo Silveira Coutinho ${ }^{4}$, Eveliny de Oliveira Eleuterio ${ }^{5}$, Alex Gradowski Adeodato ${ }^{6}$, Cássia Maria Molinaro Coelho²

'Veterinarian, MSc. Programa Pós-Graduação em Medicina Veterinária (PPGMV), Departamento de Medicina e Cirurgia Veterinária (DMCV), Instituto de Veterinária (IV), Universidade Federal Rural do Rio de Janeiro (UFRRJ), Seropédica, RJ, Brazil ${ }^{2}$ Veterinarian, DSc. DMCV, IV, UFRRJ, Seropédica, RJ, Brazil.

${ }^{3}$ Physicist, MSc., Instituto de Física, Universidade Federal do Rio de Janeiro, RJ, Brazil

${ }^{4}$ Veterinarian, Resident. Programa de Residencia em Medicina Veterinária - Clínica Médica de Animais de Companhia, DMCV, IV, UFRRJ, Seropédica, RJ, Brazil.

${ }^{5}$ Veterinarian, MSc., CRV Imagem (Centro de Referência Veterinária), Rio de Janeiro, RJ, Brazil

${ }^{6}$ Veterinarian, DSc., CRV Imagem (Centro de Referência Veterinária), Rio de Janeiro, RJ, Brazil
\end{abstract}

\begin{abstract}
This work aims to report the use of computed tomography (CT) and 3D printing technology in the diagnosis of dynamic instability with spinal compression, and the planning of cervical stabilization surgical of a 3-month-old canine with congenital cervical malformations. The patient had non-ambulatory tetraparesis, and a radiograph showed the fusion of the vertebral bodies from C3 to T3. A CT scan pinpointed the site of the spinal compression and revealed dynamic instability and severe spinal compression between the $\mathrm{C} 2-\mathrm{C} 3$ vertebrae. Tomographic images were processed to print a 3D prosthesis of the patient's craniocervical-thoracic region to optimize and plan the necessary surgery. After studying the 3D prosthesis and selecting the surgical implants required, cervical stabilization surgery through ventral access was performed. The patient's clinical improvement was rapid and progressive. Fifteen days post-surgery he was already in a quadrupedal position, after approximately 50 days he started walking again. In a year and a half of follow-up, the patient did not present any recurrence of the clinical signs. The conclusion was that CT and 3D printing contributed substancially for the clinical and surgical management, inferring quality, precision, and agility in the therapy undertaken.
\end{abstract}

Keywords: cervical stabilization, 3D printing, neurology, block vertebrae.

\section{Resumo}

Este trabalho tem por objetivo relatar o auxílio da tomografia computadorizada (TC) e uso da tecnologia de impressão 3D no diagnóstico da instabilidade dinâmica e compressão medular, e planejamento da estabilização cirúrgica cervical de um canino de 3 meses de idade com malformações congênitas cervicais. O paciente apresentava tetraparesia não deambulatória, com fusão dos corpos vertebrais de C3 a T3 na radiografia. Realizou-se TC que revelou instabilidade dinâmica e compressão medular severa entre as vértebras C2-C3. Para otimizar e planejar a cirurgia, as imagens tomográficas foram processadas para impressão de prótese 3D da região crânio-cérvico-torácica do paciente. Após estudo minucioso da prótese 3D e seleção dos implantes cirúrgicos, realizou-se cirurgia de estabilização cervical pelo acesso ventral. A melhora clínica do paciente foi rápida e progressiva. Com 15 dias de pós-cirúrgico já se mantinha em posição quadrupedal, e com aproximadamente 50 dias voltou a andar. Em um ano e meio de acompanhamento o paciente não apresentou recidiva dos sinais clínicos. Conclui-se assim, que a TC e a de impressão 3D foram contribuíram substancialmente para a conduta clínico-cirúrgica, inferindo qualidade, precisão e agilidade na terapia estabelecida.

Palavras-chave: estabilização cervical, impressão 3D, neurologia, vértebras em bloco.

\section{BJ $\mathrm{M}$ \\ Brazilian Journal of Veterinary Medicine}

p-ISSN 0100-2430

e-ISSN 2527-2179

อ
How to cite: Fernandes, M. E. S. L., Silva, R. S., Lima, L. R., Ramos, L. R., Peixoto, A. J. R., Brock, G. W., Coutinho, J. E.S., Eleuterio, E. O., Adeodato, A. G., Coelho, C. M. M. (2021). Congenital dynamic cervical instability in a dog: the role of computed tomography and 3D printing to plan and optimize the surgical approach. Brazilian Journal of Veterinary Medicine, 43, e000921. https://doi. org/10.29374/2527-2179.bjvm000921

Received: Março 04, 2021.

Accepted: Maio 30, 2021.

\section{*Correspondence}

Maria Eduarda dos Santos Lopes Fernandes Programa de Pós-graduação em Medicina Veterinária, Instituto de Veterinária, Universidade Federal Rural do Rio de Janeiro - UFRRJ

Rua Vila Ramos 20A - Casa 1, Boa Esperança CEP 23894-618 - Seropédica (RJ), Brasil E-mail:dudalopesfer@hotmail.com 


\section{Introduction}

Congenital cervical malformations are morphofunctional changes in the vertebrae commonly reported in small animals, which occur in the period of embryonic or fetal development due to multifactorial causes (Kaplan et al., 2004). Despite manifesting themselves in different breeds of dogs, they have a high incidence in chondrodystrophic breeds, especially in Bulldogs (Bailey \& Morgan, 1992).

Most malformations in the cervical spine of dogs are asymptomatic and they are often accidental radiographic findings without any clinical relevance (Westworth \& Sturges, 2016). Cases where such deformities result in dynamic instability and spinal compression, causing clinical signs ranging from cervical pain to quadriplegia are rare. However, such cases require surgical stabilization to provide the animal with expectation and quality of life (Fernandes et al., 2019). Surgical therapy presents a high risk and is complex, either due to the young age and due to the small size of the patients, as well as the proximity of vital structures (Westworth \& Sturges, 2016). Similar cases in humans are inseparable from the use of advanced imaging resources, such as computed tomography (CT) and magnetic resonance imaging (MRI), which allow an accurate diagnosis of the location and degree of spinal compression (Kawakami et al., 2009). Furthermore, models based on 3D printing technology are used for planning and training (Ishikawa et al., 2011).

Thus, this work reports the use of advanced imaging technology and 3D printing for cervical stabilization surgery in a canine puppy with cervical congenital malformations.

\section{Case report}

It was seen in the Veterinary Hospital/UFRRJ, a three months old mixed breed dog (MBD), who, according to his history, had been rescued 30 days ago and was unable to walk although he had received calcium supplementation and unsuccessful homeopathic treatment.

The clinical examination reported that the animal was alert, with a body score of $3 / 5$ (Burkholder \& Toll, 2000), and had normal puppy behavior. A neurological examination revealed non-ambulatory tetraparesis, alternating position between lateral and sternal decubitus. An assessment of the thoracic limbs (TM) showed that there was an absence of proprioception, increased extensor, and spastic tone, especially in the right TM with decreased flexor reflex; in the pelvic limbs (PM), there was a proprioceptive deficit while the spinal reflexes were normal. Nociception was preserved in the four limbs (Figure 1).
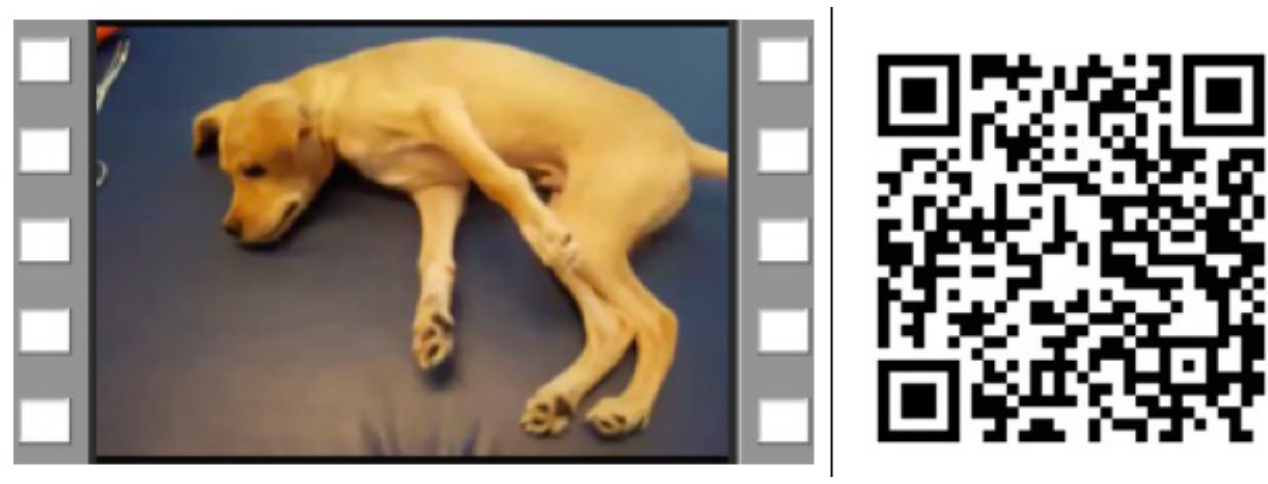

Figure 1. Clinical and therapeutic evolution of a 3-month-old male MBD dog, with congenital vertebral malformations. (Veterinary Hospital/UFRRJ- August/2019). Scan the QR Code to watch the video.

Inspection and palpation evidenced that the neck presented a "shortening" posture, with evident cervical kyphosis and permanent flexion of the head. The systemic clinical and laboratory evaluation did not show any significant changes. An X-ray (latero-lateral and ventrodolsal projections) of the cervical and thoracic regions showed an important dorsal deviation of the longitudinal axis between the C2-C3 vertebrae, with a distancing of their vertebral bodies. An alteration in the conformation, with a shortening and remodeling of the vertebral bodies from C3 to T3 with block vertebral formation and scoliosis was also observed (Figure 2). 

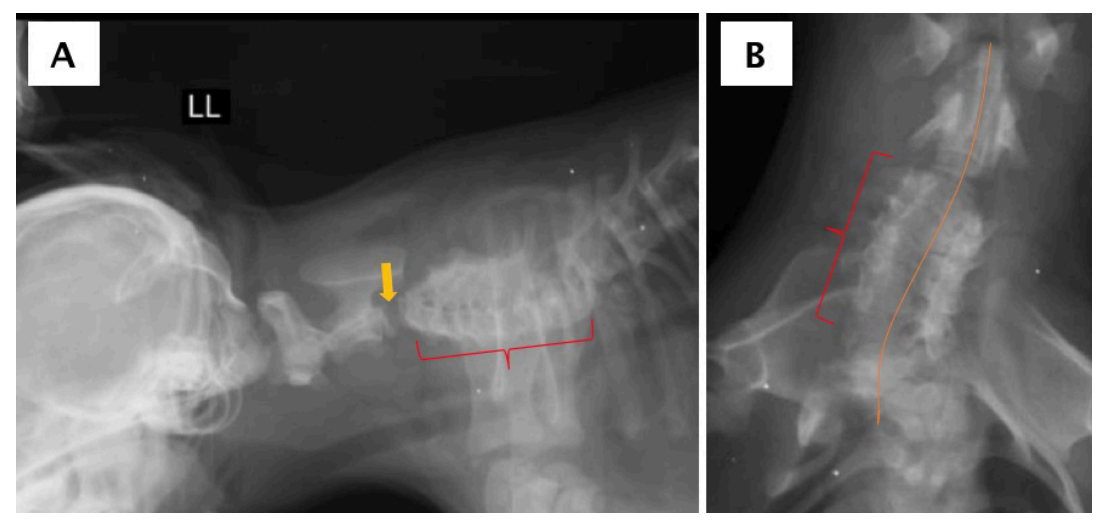

Figure 2. Radiographic images of the cervical-thoracic region of a 3-month-old male MBD dog, with congenital vertebral malformations. (Veterinary Hospital/UFRRJ - August/2019)

Note. A) Lateral-lateral radiograph showing dorsal deviation of the bone axis between the C2-C3 vertebrae, with distancing of their vertebral bodies (yellow arrow), change in conformation, with shortening and remodeling of the vertebral bodies from C3 to T3 showing block vertebral formation (red bracket). B) Ventrodorsal radiograph showing spinal block formation of C3-T3 (bracket) and scoliosis (orange curved line)

In order to obtain a more accurate diagnosis of the anatomical changes and spinal compression, a helical CT scan was performed according to the following protocol: craniocervical-thoracic region, 343mm X1673mm Scan Field of View (SFOV), slice size of $2 \mathrm{~mm}$ (79 slices), matrix 512mm X 512mm, 120V kVp and 120 amps. This exam demonstrated an important dorsal deviation of the longitudinal axis between the $\mathrm{C} 2$ and C3 vertebrae, with a distancing of their vertebral bodies that resulted in stenosis of the vertebral canal and marked spinal cord compression (Figure 3).
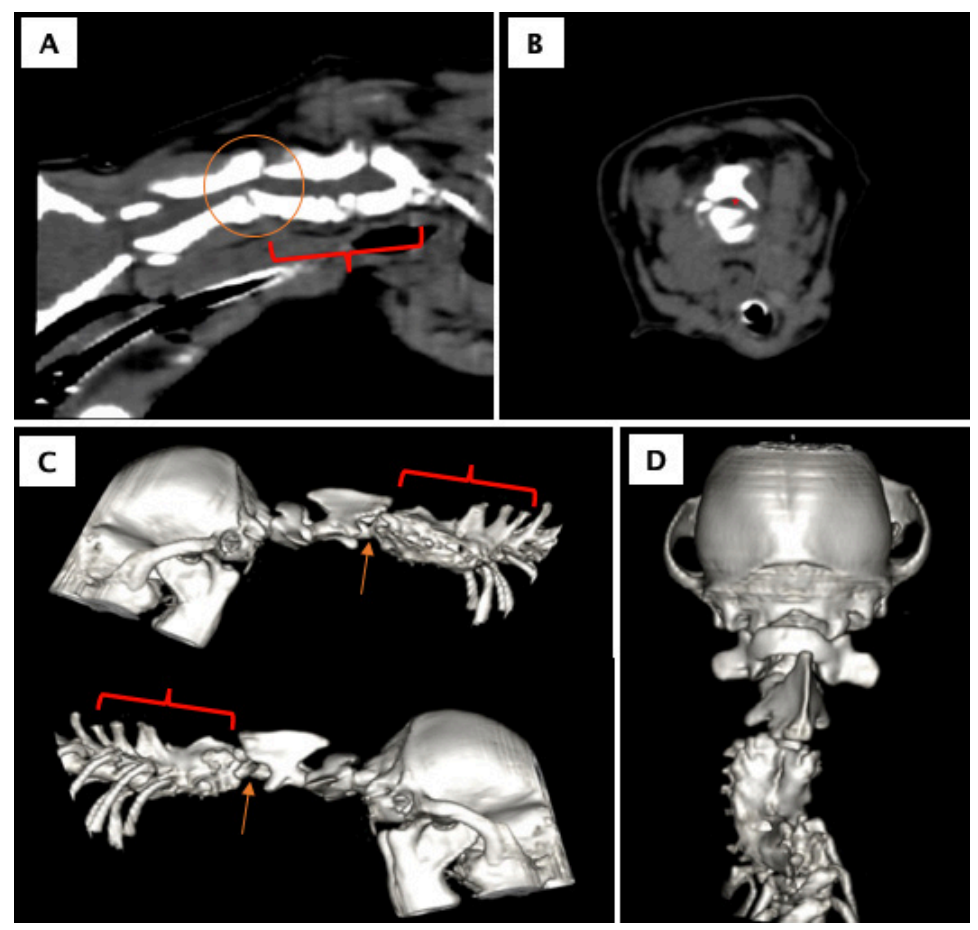

Figure 3. CT images and 3D reconstructions of the cranio-cervico-thoracic region of a 3-month-old male MBD dog, with congenital vertebral malformations. (Veterinary Hospital/UFRRJ - August/2019)

Note. A) CT image of the cranio-cervico-thoracic region, with helical acquisition and $2.0 \mathrm{~mm}$ cross-section, showing an important dorsal deviation of the bone axis between the C2 and C3 vertebrae (orange circle), resulting in canal stenosis and marked spinal cord compression. In addition, shortening and remodeling of the vertebral bodies from C3 to T3 (block formation) (red bracket) was observed. B) CT image of the C2-C3 segment of the cervical spine, with helical acquisition and $2.0 \mathrm{~mm}$ cross-section, showing stenosis of the canal and marked spinal cord compression (red asterisk). C) 3D reconstruction of the lateral cranio-cervico-thoracic region (top image - left view/ botton image - right view), showing shortening and remodeling of the vertebral bodies from C3 to T3 (block formation) (red bracket) and its dorsal deviation in relation to the $\mathrm{C} 2$ vertebra (orange arrow). D) 3D reconstruction of the dorsal cranio-cervico-thoracic region showing spinal block formation of C3-T3 and scoliosis. 
Besides, shortening and remodeling of the vertebral bodies from C3 to T3 (block formation with scoliosis) (Figure 3), loss of anatomical conformation of T2 and T3, and spina bifida (Figure 4) were observed; however, all without any clinical relevance since they did not cause spinal canal stenosis.
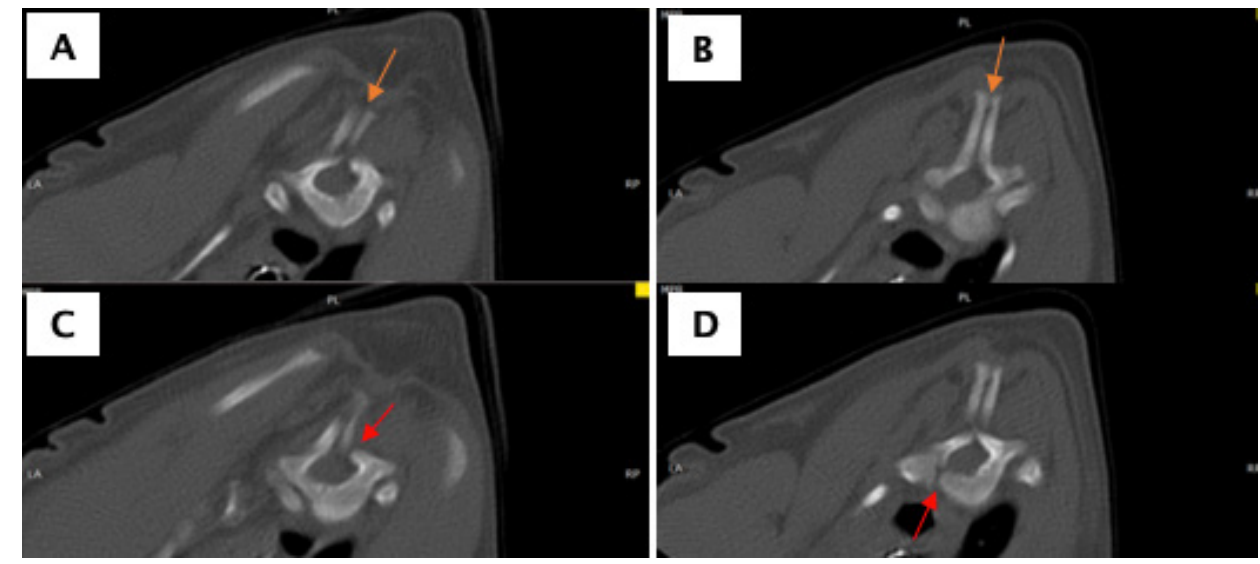

Figure 4. CT images of the cranial segment of the thoracic spine (T2 and T3 vertebrae) of a 3-month-old male MBD dog, with congenital vertebral malformations. (Veterinary Hospital/UFRRJ - August/2019)

Note. A and B) CT image of the cranial segment of the thoracic spine, with helical acquisition and 2.0 mm cross-section, showing morphological changes associated with slight modification of the shape of the vertebral bodies of T2 (A) and T3 (B), with complete median dorsal hypoplasia of the respective spinous processes (spina bifida) (orange arrows). C and D) CT image of the cranial segment of the thoracic spine, with helical acquisition and $2.0 \mathrm{~mm}$ cross-section, showing focal areas of discontinuity in the blade of the right dorsal arch of T2 (C) and in the pedicle of the left vertebral arch of T3 (D) (red arrows).

The results of the CT exam determined the need for surgical stabilization of the C2-C3 space for spinal decompression. Thus, for a complete viewing of the complex anomalies of all cervical bone structures that would be accessed directly or indirectly, we chose to print a 3D model of the skeleton from the craniocervical junction to the first thoracic vertebrae (Figure 5). First, the raw CT images in a DICOM file were exported to the Slicer ${ }^{\circledR}$ segmentation program (version 4.10.2) to segment the tissue and region of interest (ROI). Then the Laplace filter was used to smooth the surface and this surface file was exported in STL (Standard Triangle Language) format using the Meshlab ${ }^{\circledR}$ software (version 2016.12). Using the PrusaSlicer ${ }^{\circledR}$ program (version 2.1.1) the STL model was sliced and the surface information was transformed into commands to print the 3D prosthesis. The anatomical model was made by a PRUSA 3D MK3S printer using a white PLA (polylactic acid) biodegradable filament, with a $0.4 \mathrm{~mm}$ tip and $0.1 \mathrm{~mm}$ between slices. The printed model was used to plan the positioning of the patient on the table, surgical access, type and size of the implants, and the location to fix the implant on the cervical vertebrae (Figure 4).

The surgery was performed with the patient in dorsal recumbency, with both shoulders flexed, and with both elbows and carpus extended (Figure 6A). A skin incision was performed using a scalpel blade $n^{\circ} 24$ in the mid-ventral cervical region, from the cricoid cartilage to the manubrium (Figure 6B). After delicate divulsion of the subcutaneous tissue and sternohyoid muscles, the trachea, esophagus, large vessels and vagus nerve were gently pulled to the left lateral region with compresses to allow access to the ventral region of the cervical vertebrae to be stabilized. According to the measurements and previous planning, a 1.2 $\mathrm{mm}$ " $\mathrm{T}$ " shaped titanium plate containing five holes was positioned and fixed to the vertebral bodies of $\mathrm{C} 2$ (two screws measuring 8mm), and C3-C4-C5 (three screws measuring 6mm) (Figure 6C). Using portable digital radiography equipment, the correct position of the plate and screws was verified during the procedure and at the end of the surgery (Figure 6D). Subsequently, the musculature and subcutaneous tissue suture were performed with 3-0 polyglactin thread and simple continuous pattern, and dermorraphy with continuous " $U$ " pattern interrupted using 3-O polyamide thread.

The postoperative therapeutic protocol consisted of amoxicillin with potassium clavulanate (22mg / kg; VO; BID; 10 days), Meloxicam (O.1mg / kg; VO; SID; 3 days), dipyrone (25mg / kg; VO; TID; 10 days) and tramadol hydrochloride (4mg / kg; VO; TID; 7 days). A 15-day rest was recommended until the stitches were removed, and thereafter physiotherapy exercises twice a week and daily 

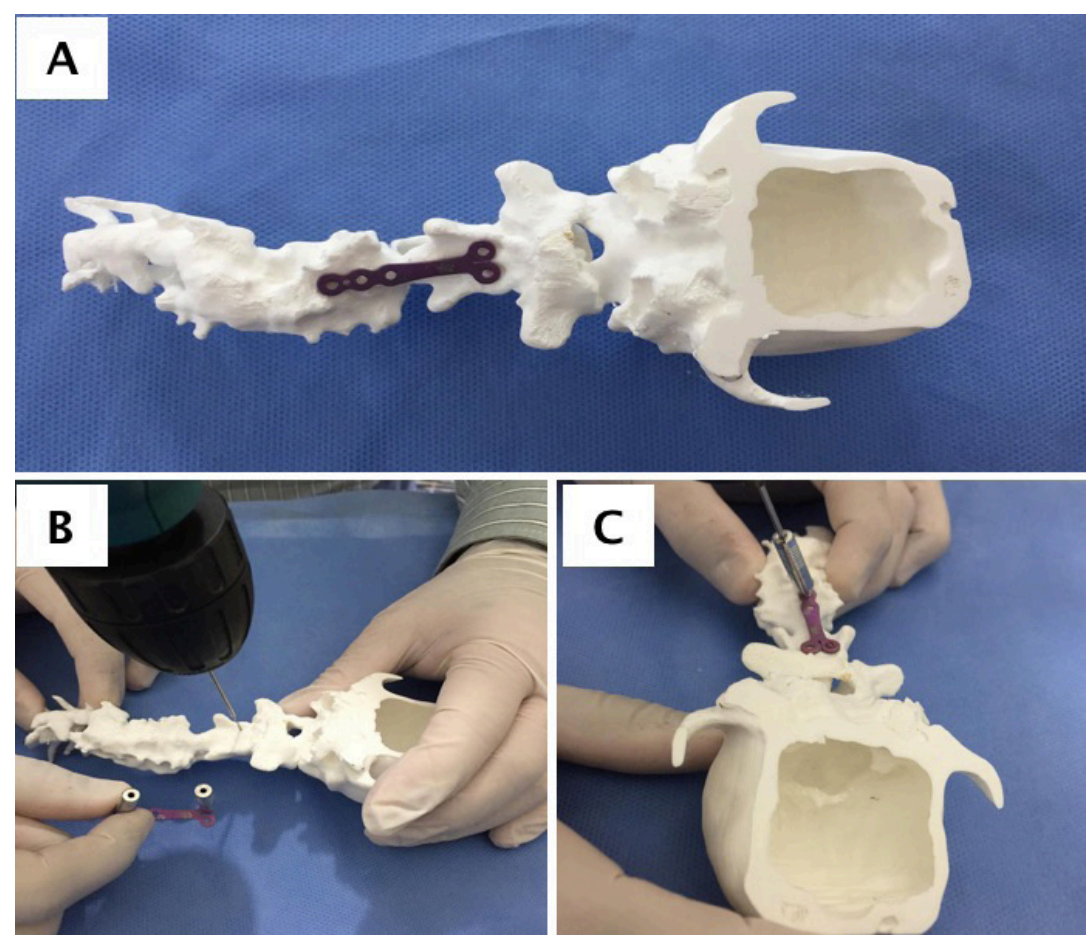

Figure 5. 3D prosthesis printed in PLA (polylactic acid) of the cranio-cervico-thoracic region of the 3-month-old male MBD dog with congenital vertebral malformations. The 3D prosthesis covered from the craniocervical junction to the first thoracic vertebrae and was used for the surgical planning of cervical stabilization. The prosthesis was decisive for better positioning of the patient on the table, surgical access, type and size of the implants and the location to fix the implant on the cervical vertebrae. (Veterinary Hospital/UFRRJ - August/2019)

Note. A) Choice of ventral access and implant (1.2mm "T" titanium plate with 5 holes) suitable for the patient using the 3D prosthesis. B) Planning of implant fixation between $\mathrm{C} 2$ and the block vertebrae using the 3D prosthesis. C) Fixation of the implants and choice of the exact stabilization site, so as not to enter the spinal canal, using the 3D prosthesis.

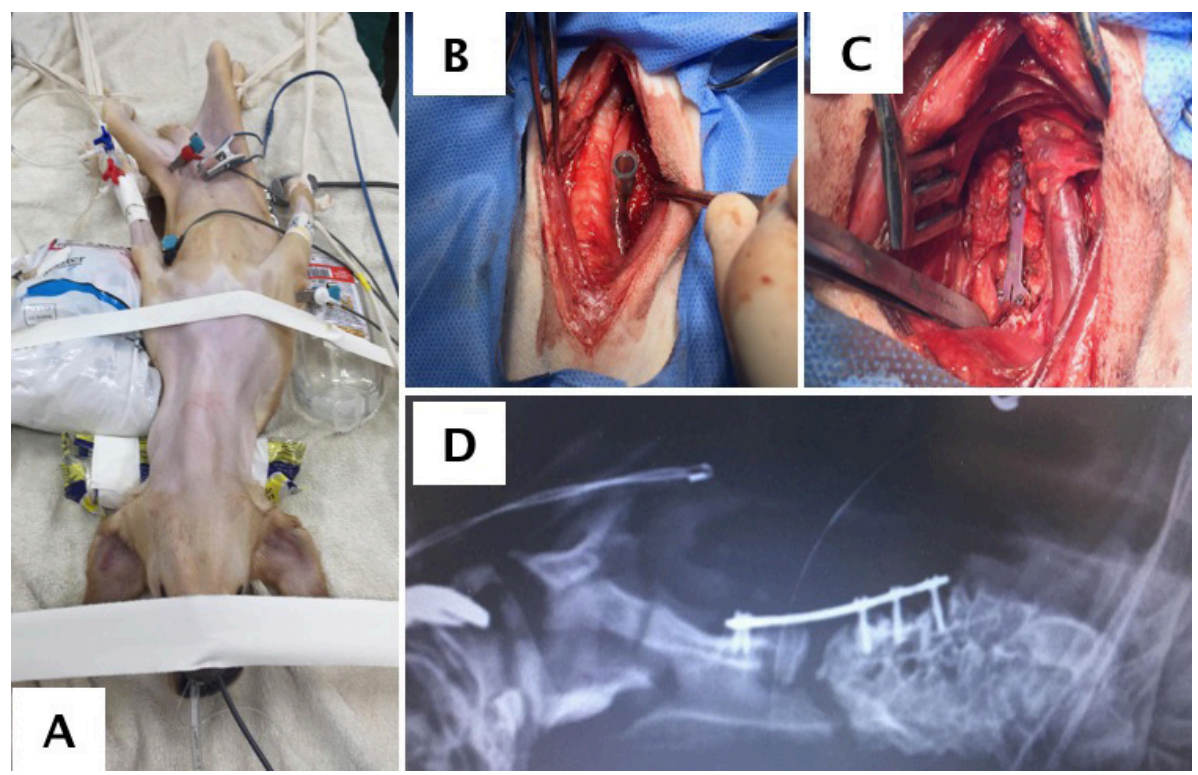

Figure 6. Surgical procedure to stabilize the cervical dynamic instability (C2-C3 vertebrae) in a 3-month-old male MBD dog with congenital vertebral malformations (Veterinary Hospital/UFRRJ - August/2019)

Note. A) Patient positioned supine for ventral access to cervical vertebrae. Note important angular deviation, shortening of the neck and scoliosis of the patient. B) Ventral access to the cervical vertebrae, with an incision along the middle cervical line, from the thyroid cartilage to the manubrium. C) As planned from the 3D model, a 1.2mm "T" shaped titanium plate containing five holes was positioned and attached to the vertebral bodies of $\mathrm{C} 2$ (2 screws measuring $8 \mathrm{~mm}$ ) and C3-C4-C5 (3 screws measuring 6mm). D) Portable digital lateral-lateral radiograph of the Trans-surgical demonstrating the correct position of the plate and screws as planned in the 3D prosthesis. 
passive exercises. The patient's clinical improvement was rapid and progressive. Although, 15 days post-surgery he was still in a quadrupedal position, after approximately 50 days he was walking (Figure1). The radiographic examination was repeated three months after surgery, showing that the implants were in their proper position, with no sign of instability or rejection, and there was a reduction in the dorsal deviation of the bone axis between C2-C3 (Figure 7). The patient was followed up for one and a half years, and during this period no recurrence of the neurological clinical condition was observed.
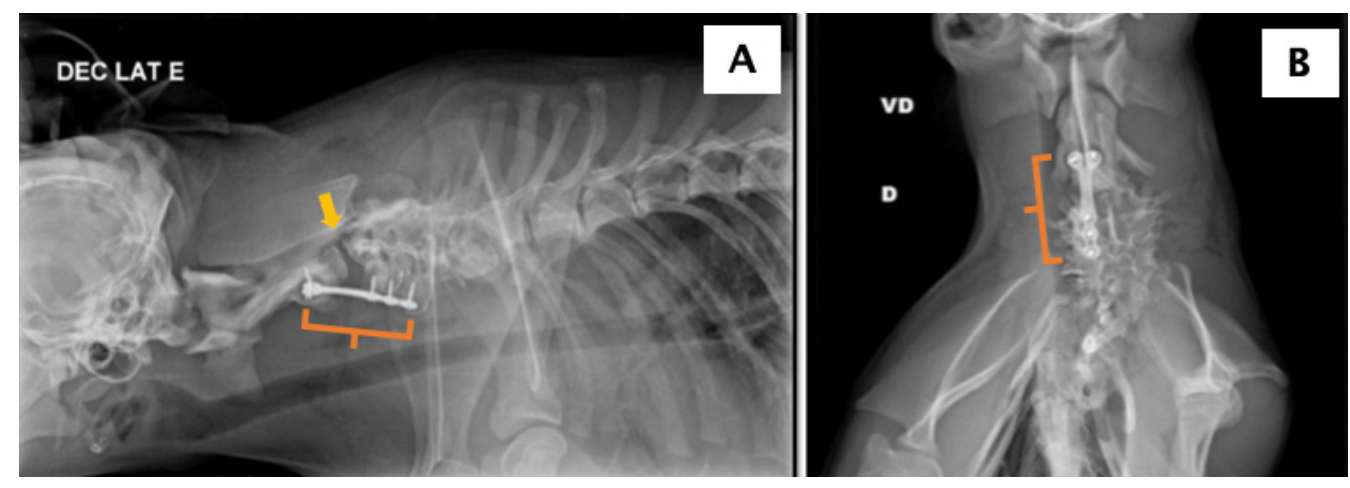

Figure 7. Radiographic images of the cervical-thoracic region of a 3-month-old male MBD dog, with congenital vertebral malformations, three months after surgical procedure to stabilize the cervical dynamic instability (C2 and C3-C4-C5 vertebrae). (Veterinary Hospital/UFRRJ- November/2019)

Note. A) Latero-lateral radiographic showing that the implants (orange bracket) were in their proper position between C2 and C3-C4-C5 vertebrae, with no sign of rejection, and there was a reduction in the dorsal deviation of the bone axis (yellow arrow) B) Ventrodorsal radiographic showing that the implants (orange bracket) were in their proper position between C2 and C3-C4-C5 vertebrae, with no sign rejection.

\section{Discussion}

This case proved to be a challenge because the animal had severe cervical vertebral anomalies with significant clinical repercussions, which is a situation that is rarely described in the literature in the canine species (De Rycke \& Saunders, 2017; Westworth \& Sturges, 2016). Biomechanical stress due to overload and dynamic vertebral instability (De Rycke \& Saunders, 2017) represented by the displacement of the bone axis between the $\mathrm{C} 2$ vertebra adjacent to the block vertebrae (C3-T3) determined not only a motor neurological dysfunction that did not allow an adequate quality of life but also the risk of imminent death if certain movements were executed abruptly.

Although vertebral malformations were easily identified by simple radiography, CT reconstruction was necessary to determine the exact location of the dynamic instability and degree of spinal compression. The visualization of the entire vertebral canal favored surgical decision-making as to where to intervene and possible repercussions of postoperative instabilities when fixing the axis.

The 3D printing of the cervical spine, based on the CT scan, allowed spatial dimensioning in addition to facilitating the study of the patient's anatomy and malformations. Furthermore, the 3D model inferred agility and precision of access to the surgical site, despite the many changes in alignment, angulation, and head and neck posture. Besides, the 3D model facilitated the choice and sizing of the implants. In human medicine, the use of 3D printing technology is widely accepted and used in cervical vertebral stabilization surgeries, providing a high degree of accuracy and safety in implant placement (Ishikawa et al., 2011; Du et al., 2020). In veterinary medicine, there are few reports of the use of 3D models for the surgical planning of patients with congenital vertebral malformations (Kamishina et al., 2019). In addition, CT and 3D printing technology are non-invasive planning techniques, which allow the training and planning of different approaches (Lorigados \& Pinto, 2013).

Undoubtedly, decompression and/or cervical stabilization surgeries are considered a challenge for the veterinary surgeon, with high rates of trans and post-surgical complications. This is mainly due to the young age and small size of the patients, who often have small and immature bones for fixing implants to, besides the prime locations are close to vital structures (Fernandes et al., 
2019; Forterre et al., 2012). One of the most common complications in these procedures is the displacement in the load distribution, causing dynamic stress in another region (Sanders et al., 2004), which, however, can be studied and simulated with the use of 3D models.

The choice of the best surgical approach for the treatment of congenital anomalies of the cervical spine is still controversial (Fernandes et al., 2019). In the case here, ventral surgical access to stabilize the cervical instability was based on the surgeon's experience, as well as on the detailed surgical planning using the 3D model, and this approach, when compared to the others (dorsal and combined access), has the highest success rate (72\% to 92\%) (Sanders et al., 2004; Schulz et al., 1997), in addition to facilitating implant fixation (Grosso et al., 2015; Sanders et al., 2004; Schulz et al., 1997).

The prognosis of patients with cervical vertebral malformations who present neurological clinical signs varies according to chronicity, the severity of the spinal cord injury, and choice of therapy (Beaver et al., 2000). In the present report, the progressive improvement of the patient's neurological clinical signs suggests that the surgical treatment was instituted correctly and at the appropriate time to avoid relapses and ensure the quality of life of the dog.

\section{Conclusion}

Computed tomography and 3D printing contributed substantially and inferred quality, precision and agility in the therapy undertaken.

\section{Ethics statement}

The responsible for the non-human animal formally consented the study.

\section{Financial support}

MESLF, LRR, AJRP, GWB - This study was financed in part by the Coordenação de Aperfeiçoamento de Pessoal de Nível Superior - Brasil (CAPES) - finance code O01. RSS, LRL, JESC, EOE, AGA, CMMC - None.

\section{Conflicts of interest}

All authors declare the absence of conflict of interest.

\section{Authors' contributions}

MESLF - PhD student in UFRRJ responsible for assisting in the clinical and surgical management of the reported case; and in the conception, design and drafting of the work.

RSS, LRL: Teachers in UFRRJ responsible for the surgical conduct of the reported case; and in the conception and revising of the work.

LRR - Master student in UFRJ responsible for planning and making the 3D impression of the cranio-cervico-thoracic spine for surgical planning of the reported case; and in the conception, design and revising of the work.

AJRP - PhD student in UFRRJ responsible for assisting in the clinical and anesthetic management of the reported case; and in the conception, design and revising of the work.

GWB, JESC - Master students in UFRRJ responsible for assisting in the neurological clinical conduct of the reported case; and in the conception, design and revising of the work.

EOE - Radiologist at CRV Imagem responsible for performing and analyzing the diagnostic images performed in the reported case; and in the conception and revision of the work.

AGA - Neurologist responsible for assisting in the management of the patient's neurological, clinical and surgical case. Founding partner of CRV Imagem, allowed and assisted in the computed tomography. Assisted in the conception and revision of the work.

CMMC - Professor in UFRRJ responsible for the clinical, surgical and anesthetic management of the reported case, team organization and public-private partnership. Responsible for the conception, design and revising of the work. 


\section{Availability of complementary results}

Online repositories: PUBMED: https://pubmed.ncbi.nlm.nih.gov, SciELO: https://scielo.org. The work was carried out at Universidade Federal Rural do Rio de Janeiro - UFRRJ, Seropédica, RJ, Brasil.

\section{References}

Bailey, C. S., \& Morgan, J. P. (1992). Congenital Spinal Malformations. The Veterinary Clinics of North America. Small Animal Practice, 22(4), 985-1015. http://dx.doi.org/10.1016/S0195-5616(92)50089-4. PMid:1641930.

Beaver, D. P., Ellison, G. W., Lewis, D. D., Goring, R. L., Kubilis, P. S., \& Barchard, C. (2000). Risk factors affecting the outcome of surgery for atlantoaxial subluxation in dogs: 46 cases (1978-1998). Journal of the American Veterinary Medical Association, 216(7),1104-1109. http://dx.doi.org/10.2460/javma.2000.216.1104. PMid:10754672.

Burkholder, W. J., \& Toll, P. W. (2000). Obesity. In Hand, M.S.; Tatcher, C.D. \& Remillard, R.L. Small Animal Clinical Nutrition (4th ed., pp. 401-430). Kansas: Mark Morris institute.

De Rycke, L. \& Saunders, J. H. (2017). Congenital anomalies of the vertebrae in dogs. Vlaams Diergeneeskundig Tijdschrift, 86(2), 105-118. http://dx.doi.org/10.21825/vdt.v86i2.16296

Du, Y. Q., Qiao, G. Y., Yin, Y. H., Li, T., Tong, H. Y., \& Yu, X. G (2020). Usefulness of 3D printed models in the management of complex craniovertebral junction anomalies: Choices of treatment strategy, design of screw trajectory, and protection of vertebral artery. World Neurosurgery Journal, 133, 722-729. http://dx.doi. org/10.1016/j.wneu.2019.09.139. PMid:31589981.

Fernandes, R., Fitzpatrick, N., Rusbridge, C., Rose, J., \& Driver, C. J. (2019). Cervical vertebral malformations in nine dogs: Radiological findings, treatment options and outcomes. Irish Veterinary Journal, 72(2), 1-13. http:// dx.doi.org/10.1186/s13620-019-0141-9. PMid:31044069.

Forterre, F., Vizcaino Reve, N., Stahl, C., Gendron, K., \& Spreng, D. (2012). An indirect reduction technique for ventral stabilization of atlantoxial instability in miniature breed dogs. Veterinary and Comparative Orthopaedics and Traumatology, 25(4), 332-336. http://dx.doi.org/10.3415/VCOT-11-07-0107. PMid:22580918.

Grosso, M. J., Hwang, R., Krishnaney, A. A., Mroz, T. E., Benzel, E. C., \& Steinmetz, M. P. (2015). Complications and outcomes for surgical approaches to cervical kyphosis. Journal of Spinal Disorders \& Techniques, 28(7), 385-393. http://dx.doi.org/10.1097/BSD.0b013e318299953f. PMid:23732179.

Ishikawa, Y., Kanemura, T., Yoshida, G., Matsumoto, A., Ito, Z., Tauchi, R., Muramoto, A., Ohno, S., \& Nishimura, Y. (2011). Intraoperative, fullrotation, three-dimensional image (O-arm)-based navigation system for cervical pedicle screw insertion. Journal of Neurosurgery. Spine, 15(5), 472-478. http://dx.doi.org/10.3171/2011.6.SPINE10809. PMid:21761967.

Kamishina, H., Sugawara, T., Nakata, K., Nishida, H., Yada, N., Fujioka, T., Nagata, Y., Doi, A., Konno, N., Uchida, F., \& Maeda, S. (2019). Clinical aplication of 3D printing technology to the surgical treatment of atlantoaxial subluxation in small breed dogs. PLoS One, 14(5), 1-18. http://dx.doi.org/10.1371/journal.pone.0216445. PMid:31050689.

Kaplan, K. M., Spivak, J. M., \& Bendo, J. A. (2004). Embryology of the spine and associated congenital abnormalities. The Spine Journal, 5(5), 564-576. http://dx.doi.org/10.1016/j.spinee.2004.10.044. PMid:16153587.

Kawakami, N., Tsuji, T., Imagama, S., Lenke, L. G., Puno, R. M., \& Kuklo, T. R. (2009). Classification of congenital scoliosis and kyphosis: A new approach to the three-dimensional classification for progressive vertebral anomalies requiring operative treatment. The Spine Journal, 34(17), 1756-1765. http://dx.doi.org/10.1097/ BRS.0b013e3181ac0045. PMid:19644327.

Sanders, S. G., Bagley, R. S., Silver, G. M., Moore, M., \& Tucker, R. L. (2004). Outcomes and complications associated with ventral screws, pins, and polymethyl methacrylate for atlantoaxial instability in 12 dogs. Journal of the American Animal Hospital Association, 40(3), 204-210. http://dx.doi.org/10.5326/0400204. PMid:15131100.

Lorigados, C. A. B., \& Pinto, A. C. B. F. (2013). Tomografia computadorizada do encéfalo do cão: Aspectos da normalidade e correlação anatômica. Arquivo Brasileiro de Medicina Veterinária e Zootecnia, 65(3), 729-734. http://dx.doi.org/10.1590/S0102-09352013000300018.

Schulz, K. S., Waldron, D. R., \& Fahie, M. (1997). Application of ventral pins and polymethylmethacrylate for the management of atlantoaxial instability: Results in nine dogs. Veterinary Surgery, 26(4), 317-325. http://dx.doi. org/10.1111/j.1532-950X.1997.tb01504.x. PMid:9232790.

Westworth, D. R., \& Sturges, B. K. (2016). Congenital Spinal Malformations in Small Animals. The Veterinary Clinics of North America. Small Animal Practice, 40(5), 951-981. http://dx.doi.org/10.1016/j.cvsm.2010.05.009. PMid:20732600. 